\title{
السلطة التقديرية للقاضي الجزائي في إيقاف تتفيذ العقوبة
}

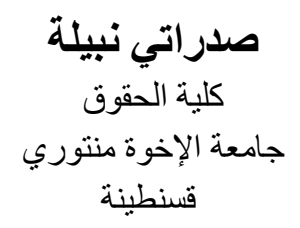

إن إيقاف تتفيذ العقوبة يعد أحد أساليب واهم دعائم التفريد

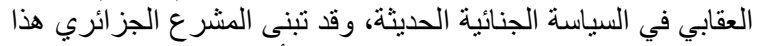

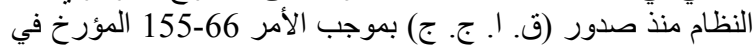
1966-6-8 وتضمنته المواد من

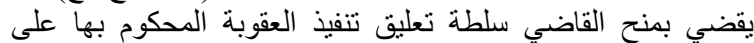

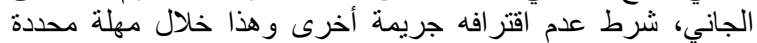

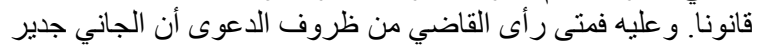

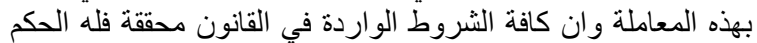

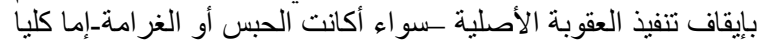

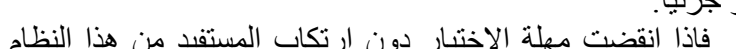

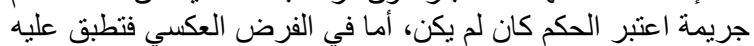
العقوبة المعلقة النفاد إلى جانب عقوبة لجن الجريمة الجديدة.

\section{Abstract:}

The stay of execution is considered as one of the most important pillars of the individualization of punishment in modern penal policy. The Algerian legislation adopted this system since the issuance of the penal procedures code under the ordinance 66-155 on June $08^{\text {th }} 1966$, and it was stipulated in the sections 592 to 595 (penal procedures code). It provides the granting of the authority to suspend the execution of a sentence imposed on the offender provided that he would not commit another crime, within a period defined by the law. Therefore 
وقد ذابت العديد من التتريعات الجنائية إلى تكريس هذا المبدأ خصوصا في المرحلة القضائية باعتبار ها

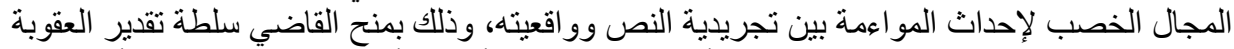

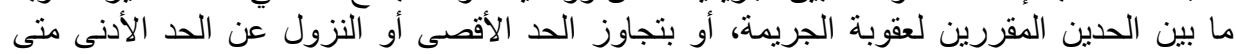
اقتضت ظروف الجريمة والجاني تثنديد العقوبة أو تخفيفها.

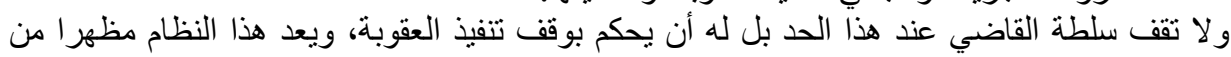

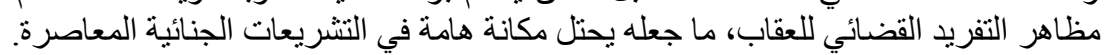

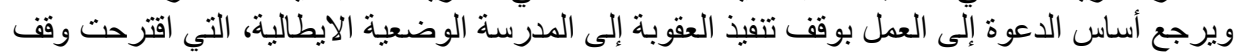

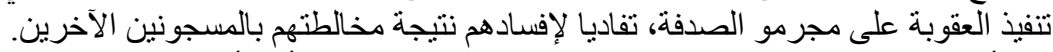

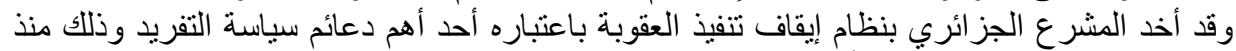

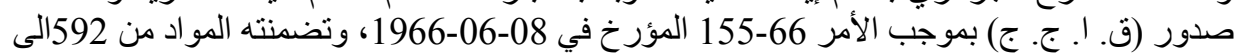

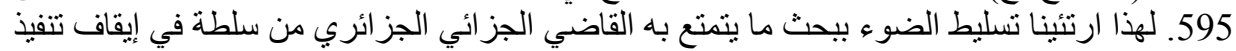

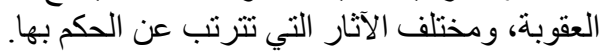

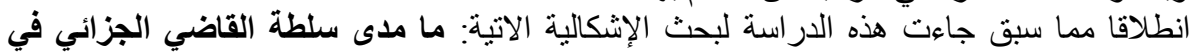
الحكم بايقاف التفيذ تفريدا للعقوبة؛ وما هي مختلف صور وقف الإنف التنفيذ التي تبناها تثريعنا

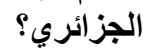

وقد اتبعنا في دراستتا هذه الخطة الثنائية، وذلك بتخصيص مطلبين، الأول تحت عنوان انتئن مفهوم إيقاف تتفيذ العقوبة، اما الثاني فأفردناه لبحث سلطة محكمة الموضوع في في إيقاف التنفيذ.

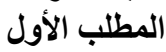

\section{مفهوم وقف تنفيذ العقوبة}

يعد نظام وقف تنفيذ العقوبة من أكبر مظاهر السلطة التقديرية المنوط بالقاضي تحقيقا للأغراض المستهدفة بتفريد العقاب(1).

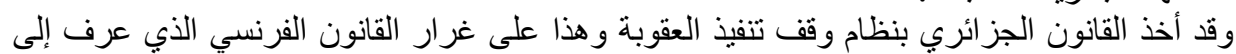

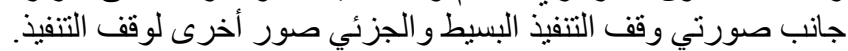

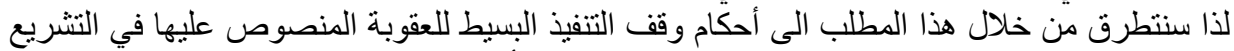

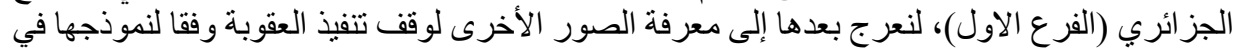
التشريع الفرنسي (الفرع الثناني).

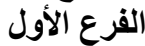
تعريف إيقاف التنفيذ البسيطوشروطه وسنتناول هذا الفرع على النحو التالي:(أولا) نعريف وقف التنفيذ البسيط و علته. (ثانيا) شروط وقف

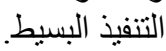
أولا-تعريف وقف البنفيذ التفيذ وعلته: 1-تعريفه: اتفق فقهاء القانون الجنائي على معنى متقارب لهذابذا النظام، إذ عرف على انها: ا(تعليق تتفيذ

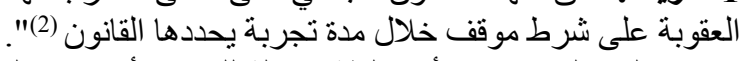

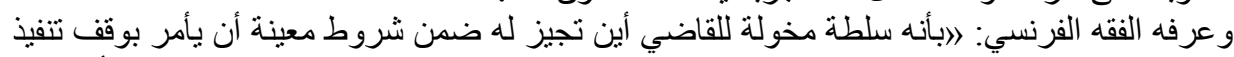

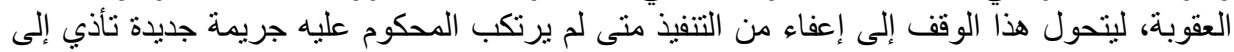
إلغاء وقف التتفيذ (3)".

كما عرف البروفيسور "جون لاغفوي" لوفئ وقف التنفيذ بأنه: الإعفاء الكلي أو الجزئي من تنفيذ العقوبة

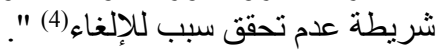
ومن ثم فان هذا النظام يفترض صدور حكم بالإدانة إلا أن هذا الأخير يوقف تتفيذه على شرط خلال مدة معينة.

2-علته: تكمن العلة الأساسية من وقف تتفيذ العقوبة بحسب المشر ع الجزائري في تقرير معاملة ممتازة

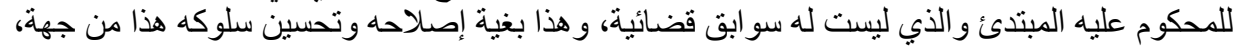


ومن جهة أخرى فهو نظام يحول دون العودة إلى ارتكاب جرائم أخرى كونه لا يخلق وضعا مستقرا

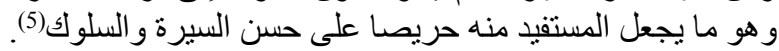

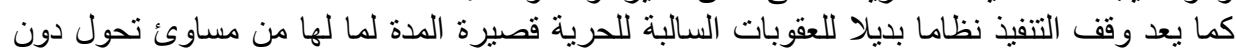

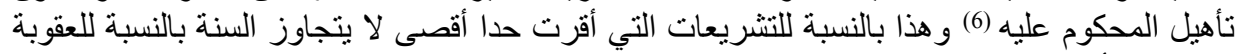
التي يمكن أن يوقف تنفيذها.

ومن اجل تطبيق نظام وقف تنفيذ العقوبة لابد من تو افر جملة من الثروط نجان نجملها في النقاط المو الية.

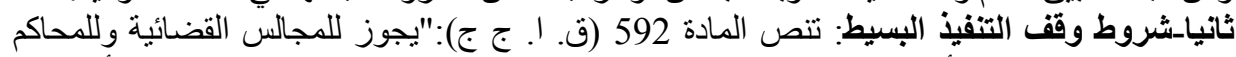

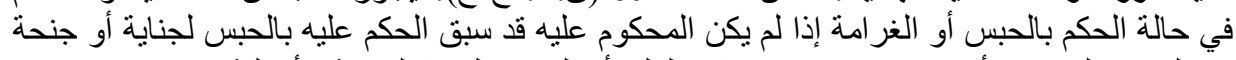

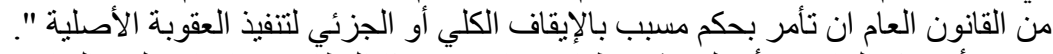

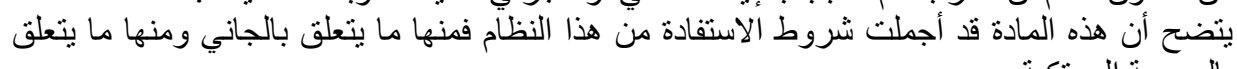

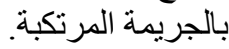

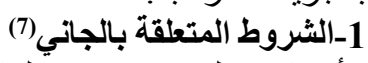

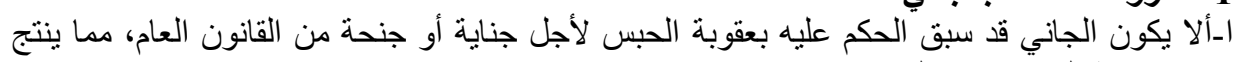

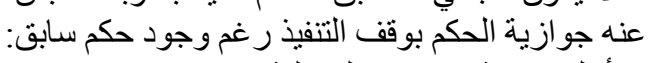

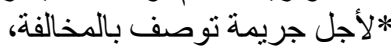

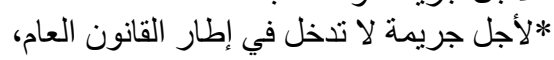

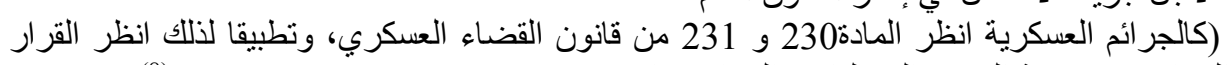

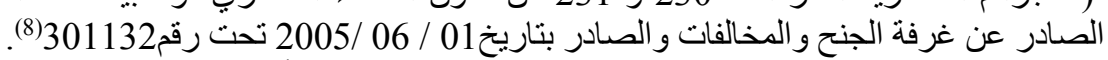
*وإذا كانت العقوبة السابقة غير الحبس كالغرامة مثلا وكذلك الأحكام التي تقضي بتدابير التربية

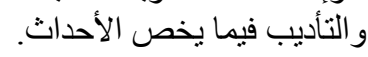

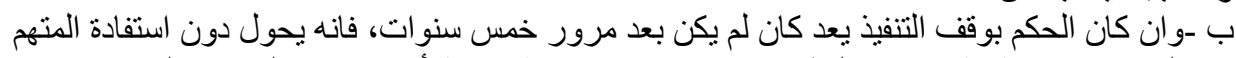

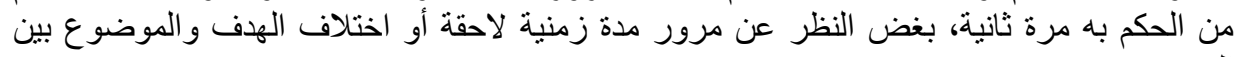

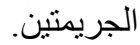

وتستدل المحكمة في الكثف عن سو ابق المتهم بالرجوع إلى سند رسمي (صحيفة السو ابق).

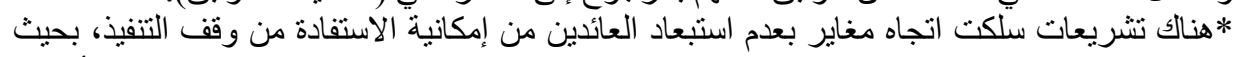

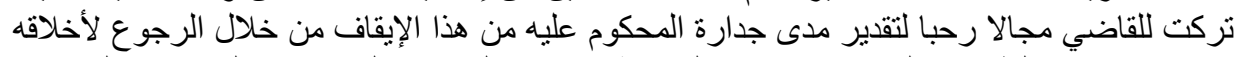

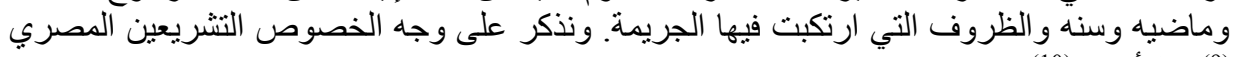
(9) (9)، والأردني (10). ونحن نؤيد هذا الاتجاه كونه بتمانشى مع منطلبات التفريد العقابي، سيما إذا تمت إفادة الدذنب بهذا النظام

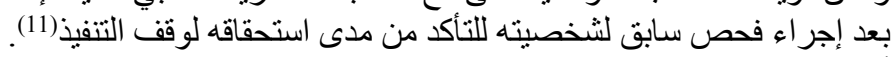

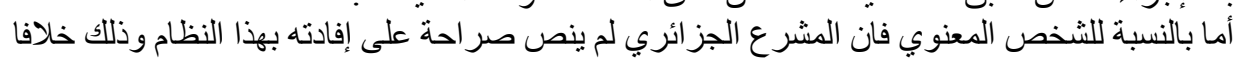

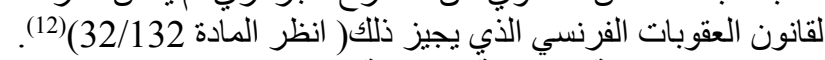

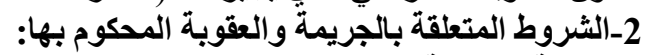

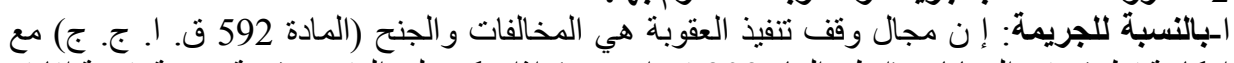

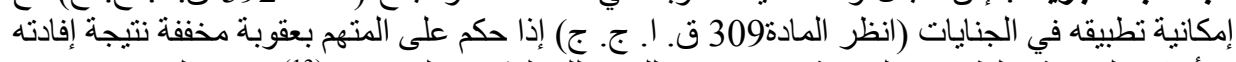

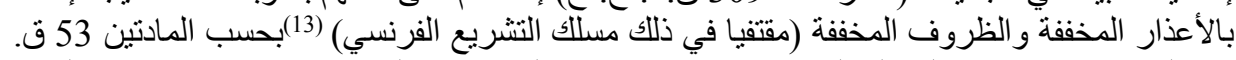

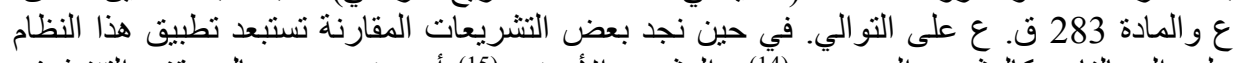

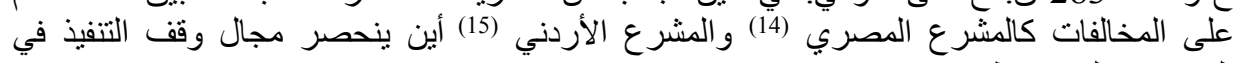
الجنايات و الجنح فقط.

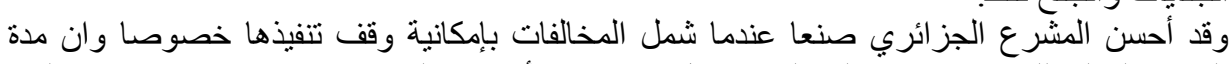

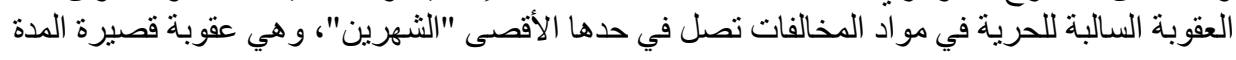


ما يؤهلها أكثر من غيرها من العقوبات إلى وقف التنفيذ وهذا بغية تجنب مساوئ العقوبات السالبة للحرية قصبرة المدة.

ب-بالنسبة للعقوبة: يشترط للحكم بايقاف التنفيذ ان تكون العقوبة المحكوم بها هي الحبس أو الغرامة

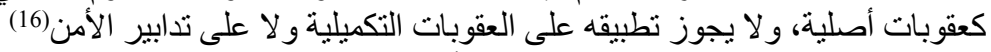

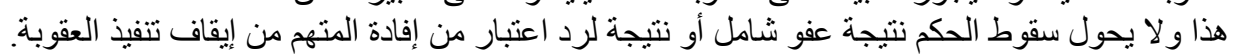

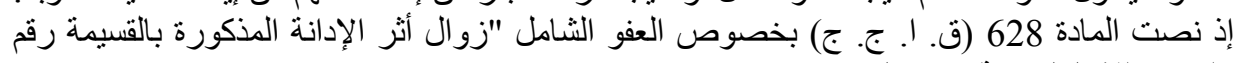

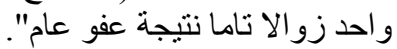

وفيما يتعلق برد الاعتبار القضائي فقد نطرقت له اله المادة692 (ق. ا. ج. ج) و التي تقضي بعدم التتويه عن

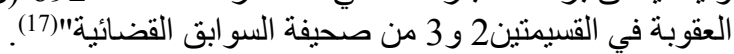

لكن هل تسري أُحكام هذه المادة على رد الاعتبار بقوة القانون على اعتبار أن المشرع قد أغلل التطرق

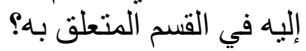

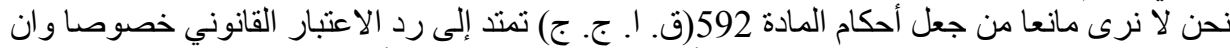

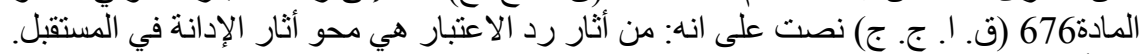

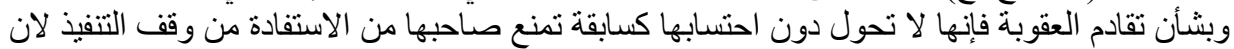

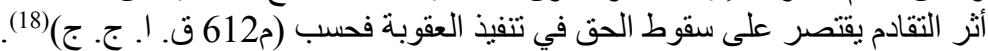

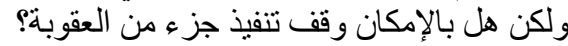

بتاريخ 1976/03/26 صدر منشور عن وزارة الإن العدل يلفت من خلالده انتباه القضاة إلى عدم جواز الحكم

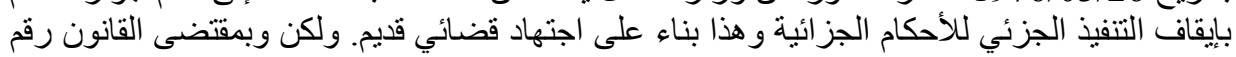

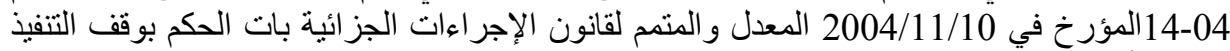

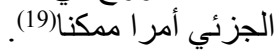

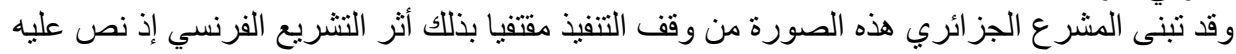

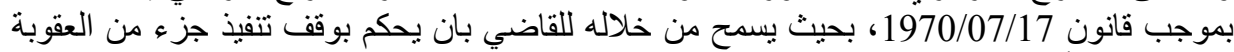

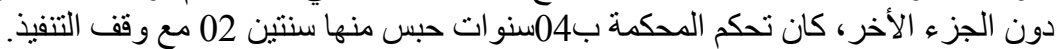

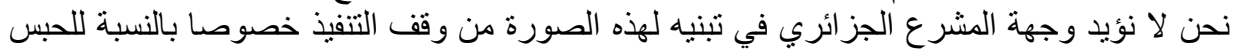

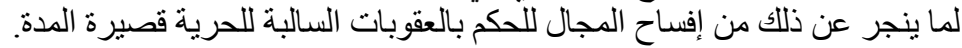

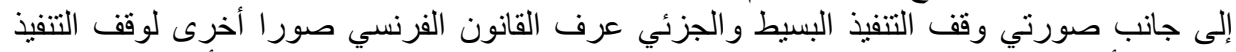
و المنمثلة أساسا في وقف التنفيذ مع الوضع تحت الاختبار ووقف التنفيذ مع الالتز ام بأداء عمل للمنفعة

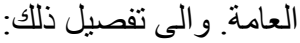

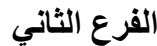

الصور الأخرى لوقف تنفيذ العقوبة الغول

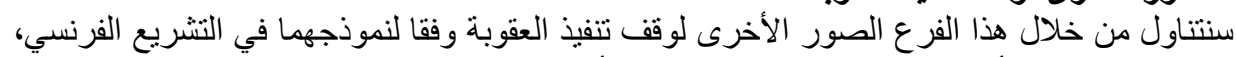
وذللك للتعرف على أحكامهما. وهذا على المي النحو المبين أدناه:

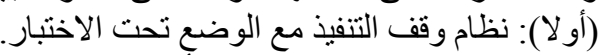

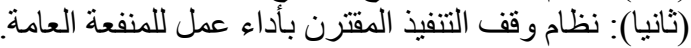

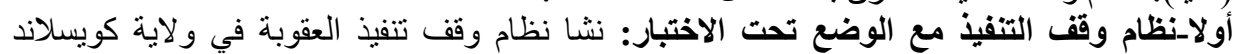

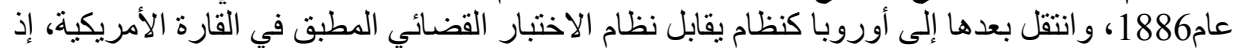

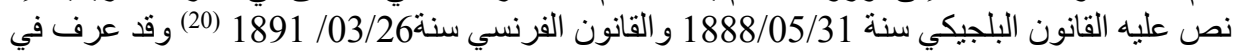

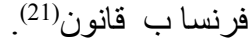

ويعود انتثار هذا النظام إلى توصيات العديد من المؤتمرات الدولية التي نادت بتطبيقه كالمؤتمر الدولي

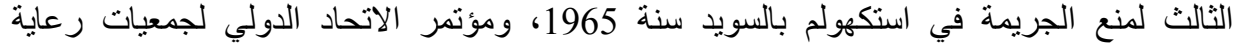
المسجونين في كيوتو باليابان 1970 1922). 


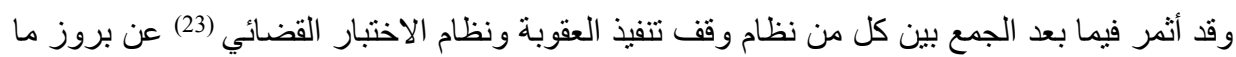

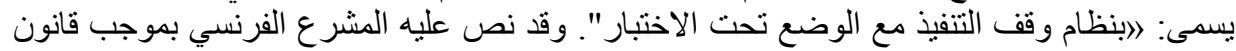

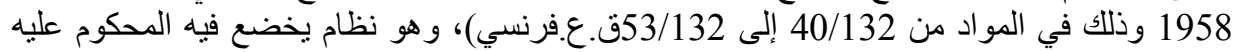

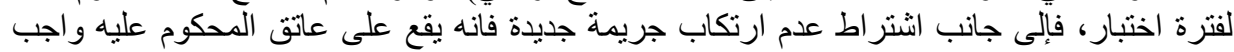

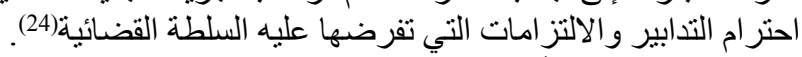

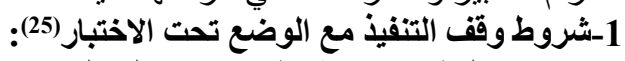

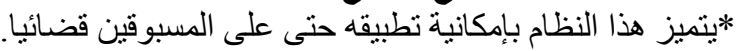

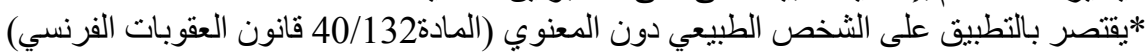

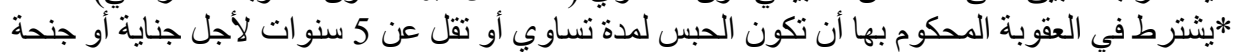

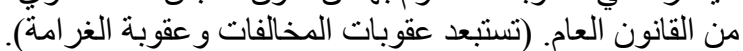

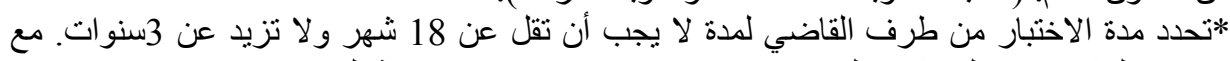

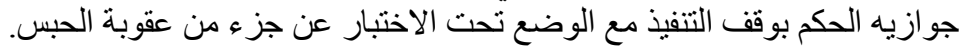
و وليه فإذا قرر القاضي إفادة الكتهم بهذا النظام فانه يترتب علئ عليه إيقاف تنفيذ العقوبة_كليا أو جزئياالدكوم بهاً إيقافا مشروطاً.

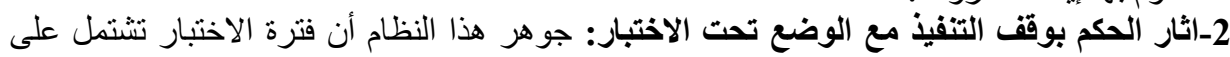

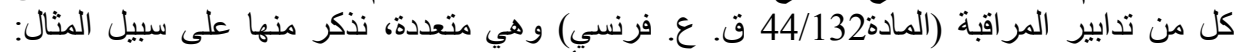

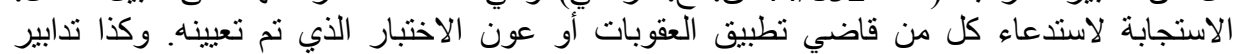

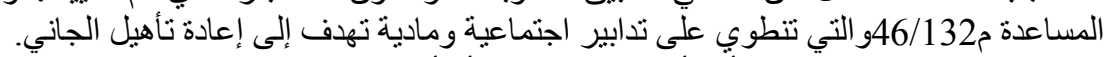

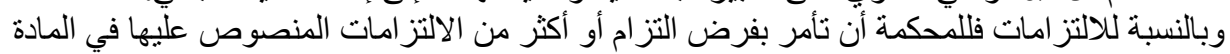

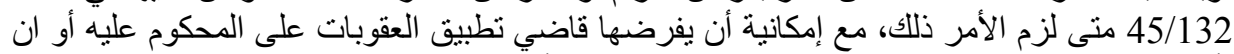

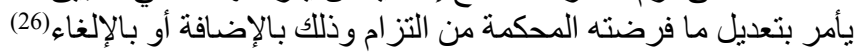

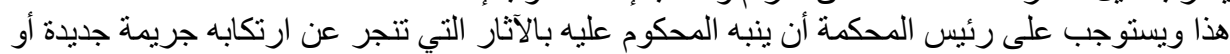

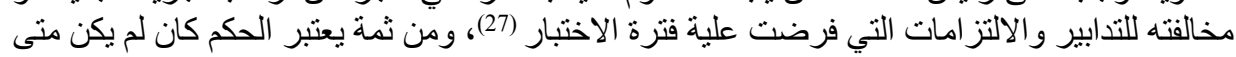

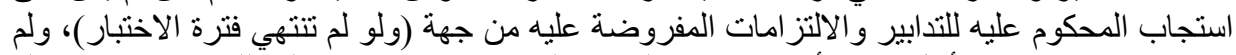

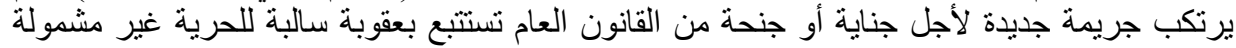

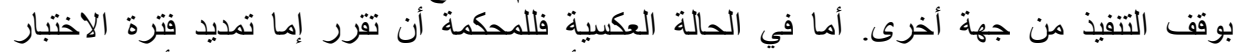

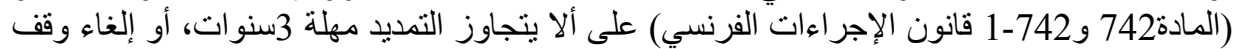

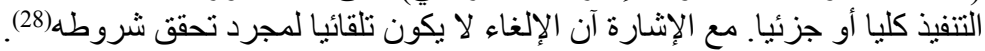

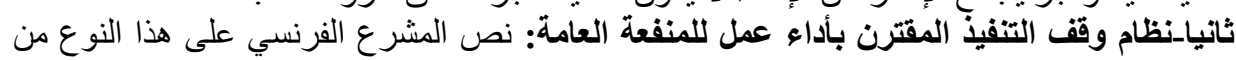

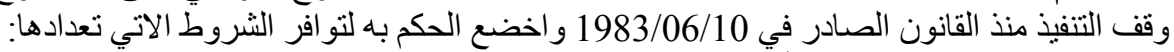

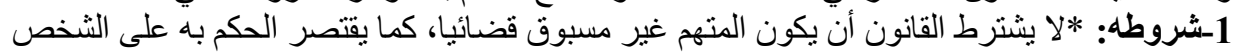

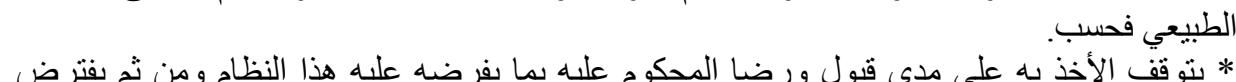

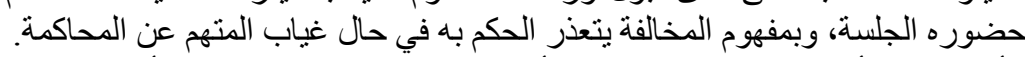
*أن يتعلق الأمر بعقوبة الحبس لجناية أو جنحة من القانون العام على على ألا تتجاوز عقوبة الحبس 05

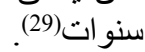

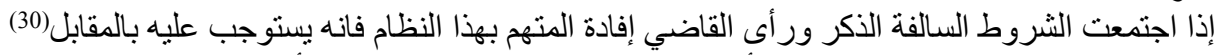

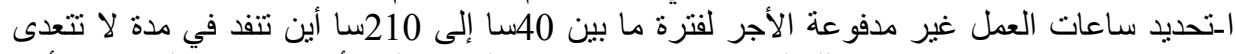

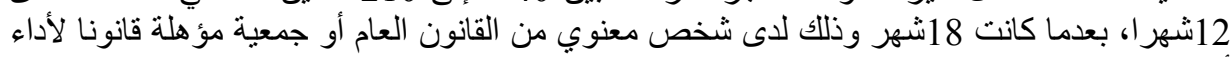




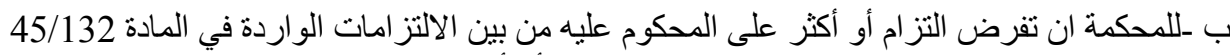

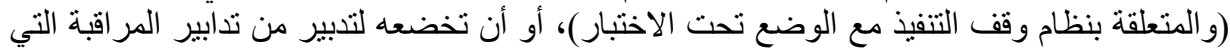

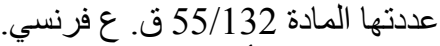

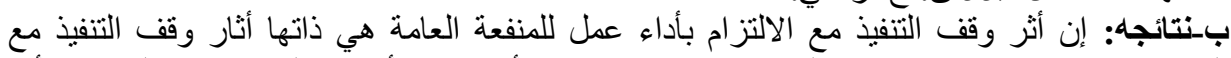
الوضع تحت الاختبار سواء ما تعلق منها بنجاح الاختبار أو حنى الأسباب التي تؤدي لإلغان لإنائه والأثر المترتب عن هذا الإلغاء(31).

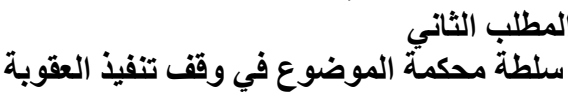

يعد نظام وقف تنفيذ العقوبة من أفضل وسائل التفريد القضائي، إذ يجيز للفئل اللقاضي استبعاد العنصر المادي

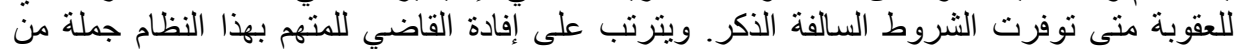
الآثار. حول هذه النقاط وغير ها ستذور المناقثات في الفروع المو الئي.

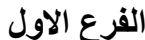

السلطة التقليرية للقاضي الجزائي في الحكم بإيقاف التنفيذ

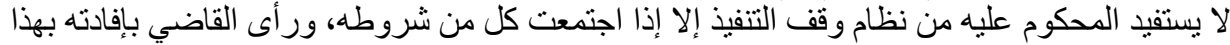

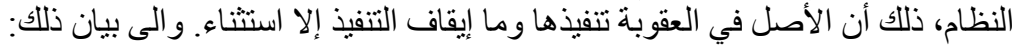

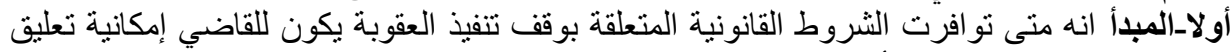

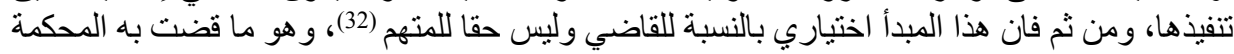

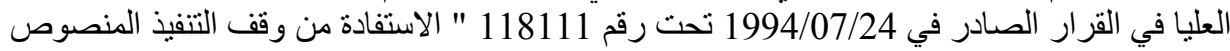

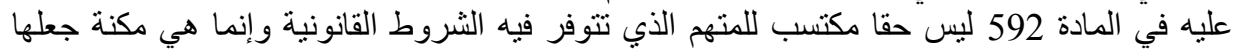

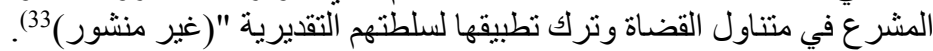

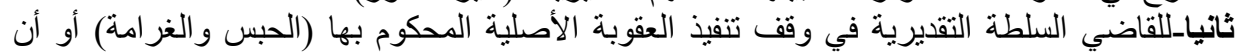

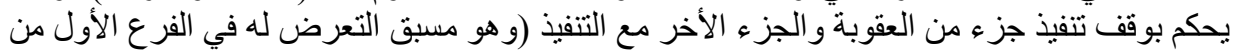

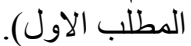
ثالثا_لما كان إيقاف التنفيذ هو خروج عن الأصل ويخضع الحكم به لسلطة القاضي التقديرية ـبعد التأكد

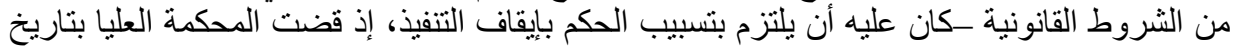

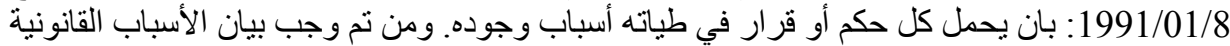

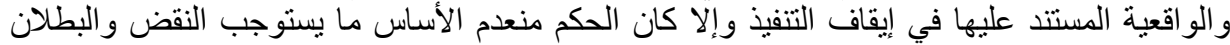

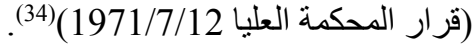

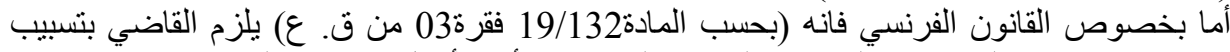

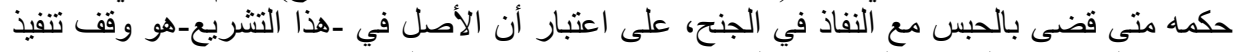

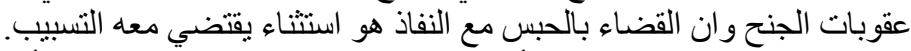

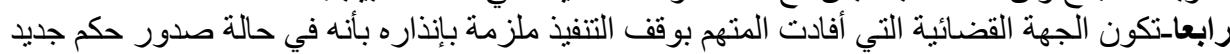

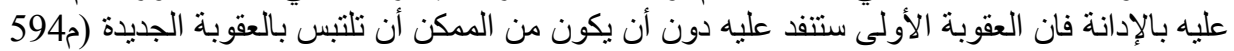

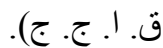

والجدير بالذكر أن قرارات المحكمة العليا الجزائية تميزت بعدم استقرارها حول أثر إغفال إنذار

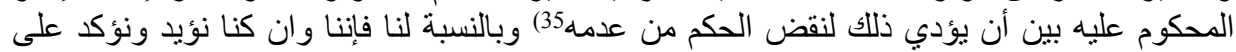

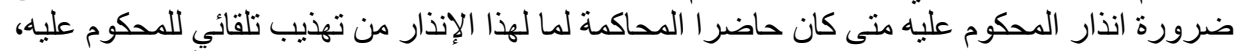

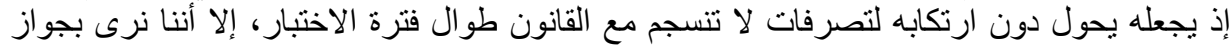

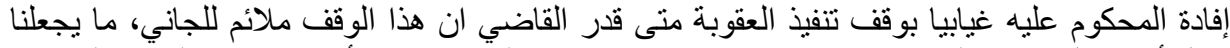

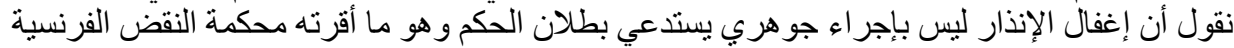
في قرار ها الصادر بتاريخ 24مارس لإن جوهري (1937). 


\section{الفرع الثاني}

اثار الحكم بوقف تنفيذ العقوبة

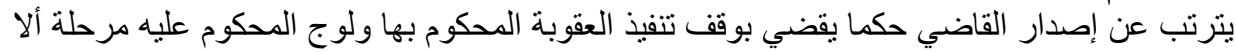

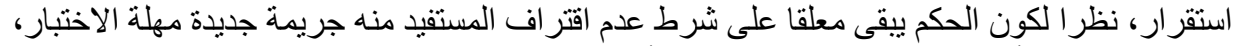

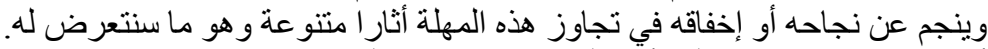

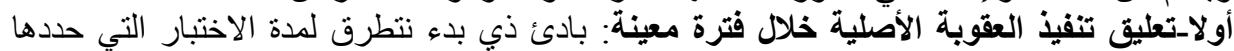

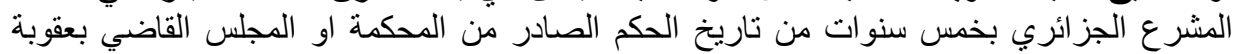

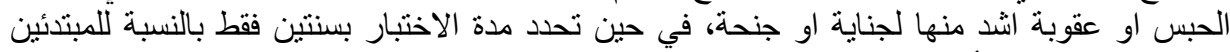

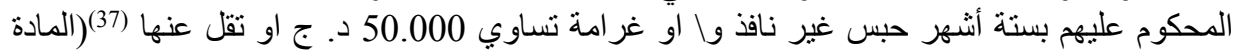

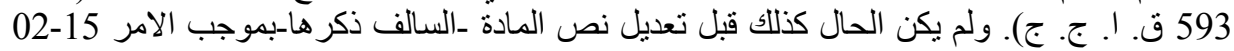

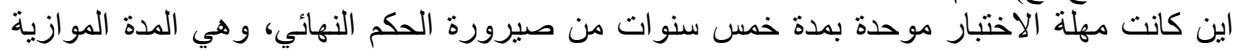

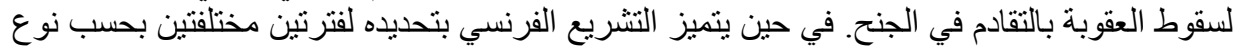

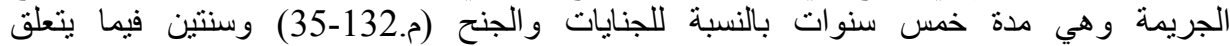
بالمخالفات(132-37.ق.ع.فرنسي)، وفي كل الأحوال بستبعد الإلغاء متى صدر حكم جديد موقوف

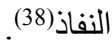

ثانيا-وضع المحكوم عليه أثناء مدة وقف التنفيذ: من اثار الحكم بوقف التتفيذ حظر اتخاذ كافة

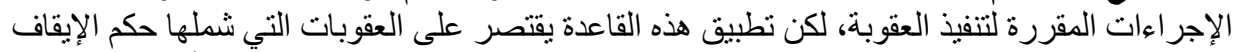

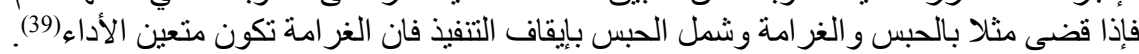

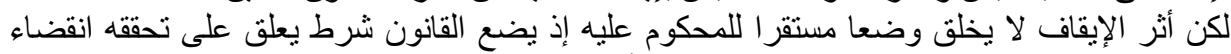

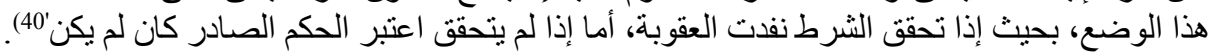

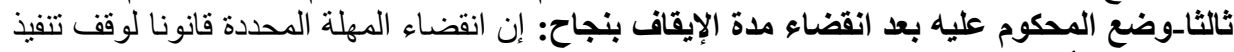

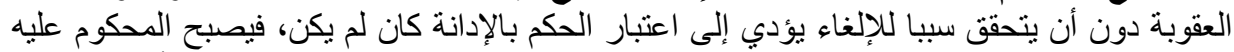

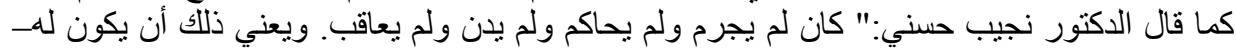

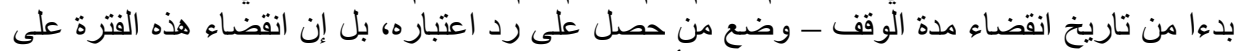

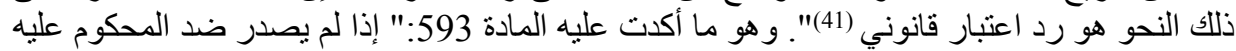

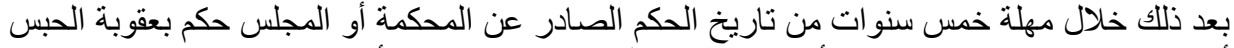

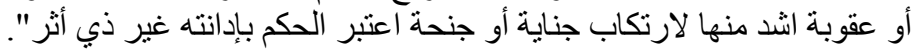

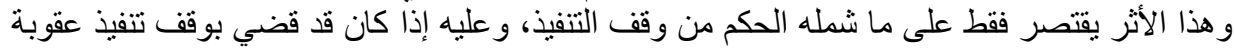

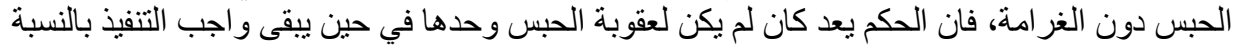

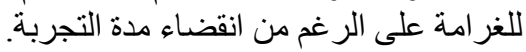

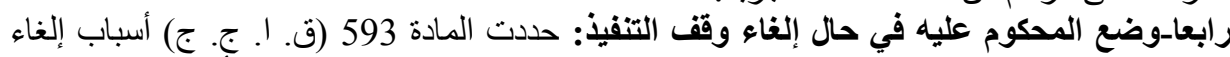

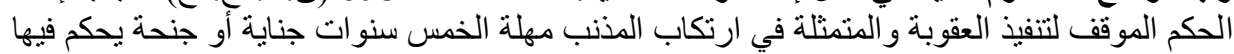

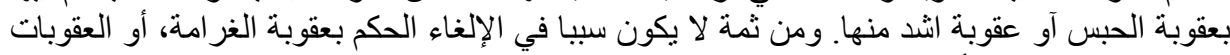

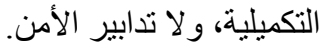

فتحقق هذه الأسباب الملغية للحكم الموقف للتنفيذ تؤذب إلى تنفيذ كل من عقوبة الجريمة الأولى كما كما تعد

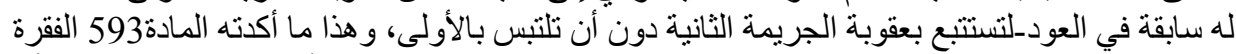

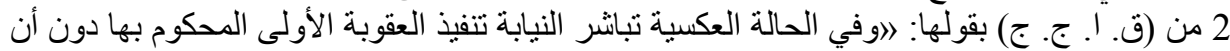
تلتنس بالعقو بة الثانية" لكن هل يتمتع القاضي الجزائي بسلطة تقديرية في إلغاء وقف تنفيذ العقوبة منى تو افرت أسبابه؟ أم أن

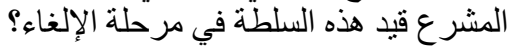
إن المشرع الجز ائري لم يقم بسن إجر اءعات معينة تتبع منى تحققت الأسباب التي تلغي وقف التتفيذ(42). 


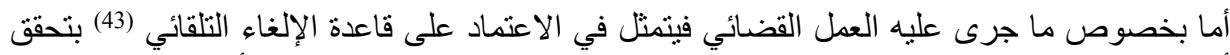

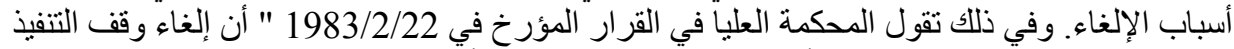

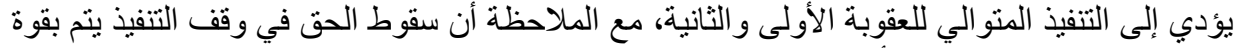

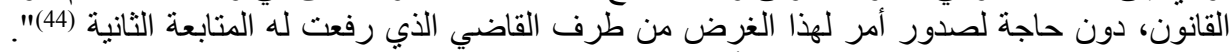

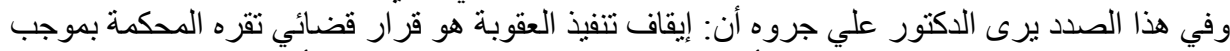

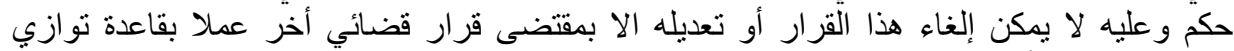

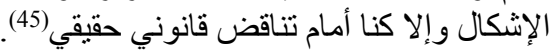

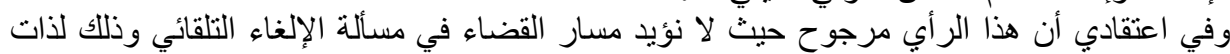

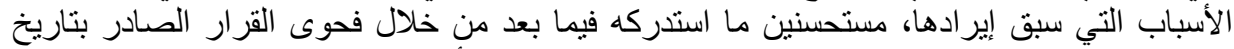

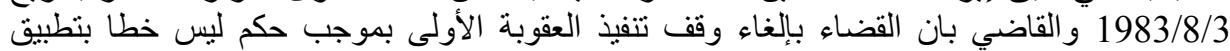
القانون (46)" و هذا الاتجاه يعد أجدر بالإتباع.

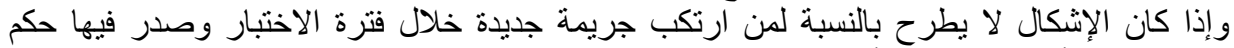

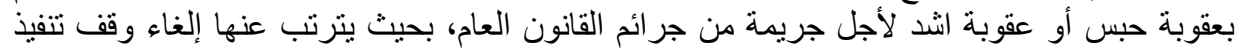

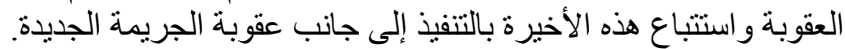

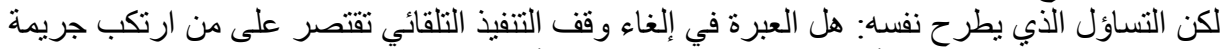

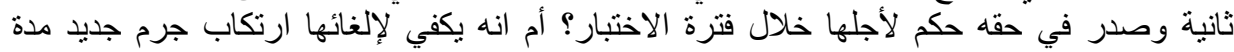

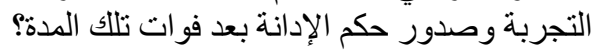

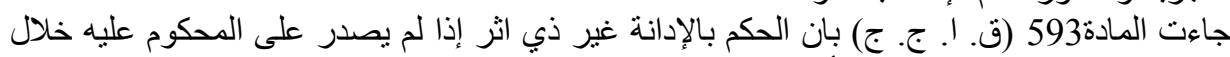

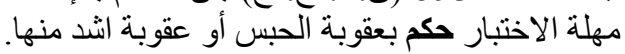

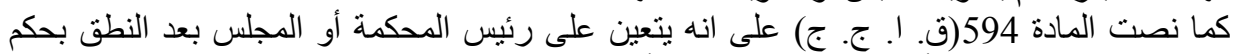

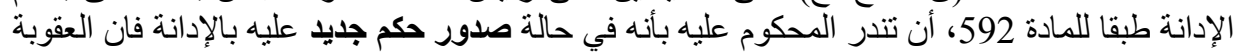

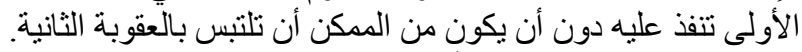

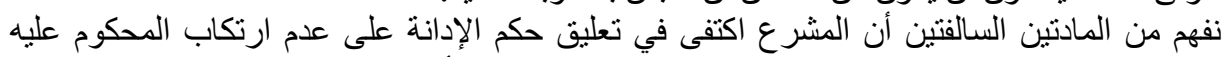

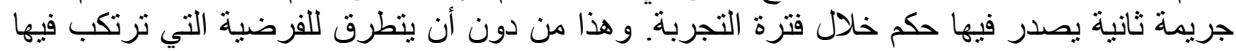

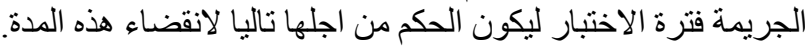

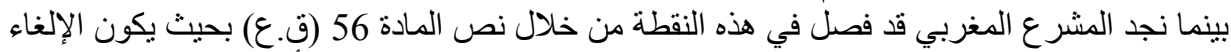

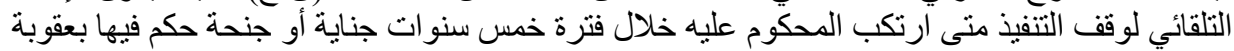

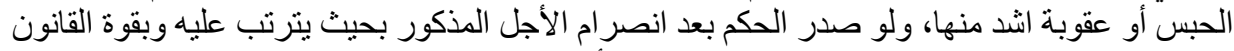
و عندما يصير الحكم نهائيا إلغاء وقف تلفيذ العيذ العقوبة الأولى قبل العقوبة الثانية دون إدماج(47)هذأها هو الاتجاه الأفضل في راينا.

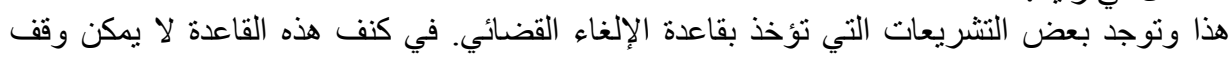

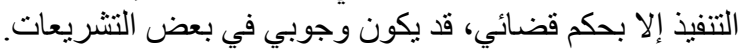

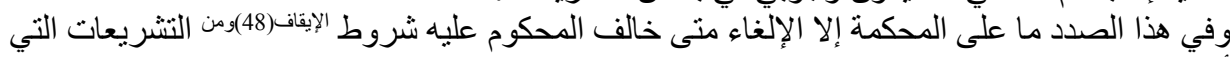

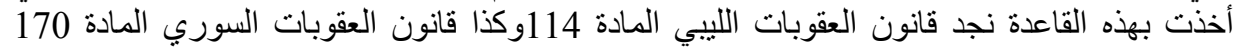

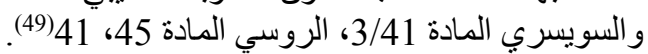

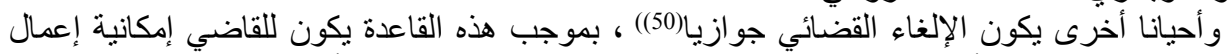

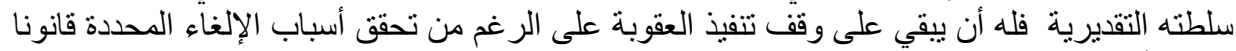

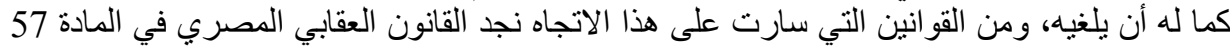

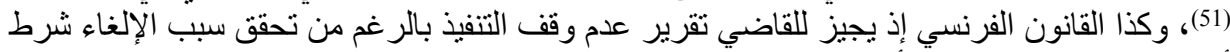
أن يكون القرار معلا، بل و أعطى للمحكوم عليه إمكانية تقديم طلب الإعفاء من الإلغاء (52) 
ويرى الدكتور حاتم حسن موسى بكار ب:" ان هذا المسلك يتيح للقاضي قدرا كبير ا من التفريد يمهد له

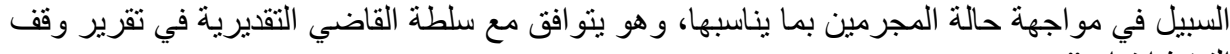

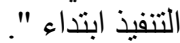

صحيح أن هذا الاتجاه يفتح بابا واسعا للقاضي في التفريد، ولكنه بالمقابل فيه إهدار لأغر اض العقال العقوبة

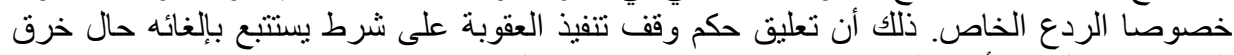

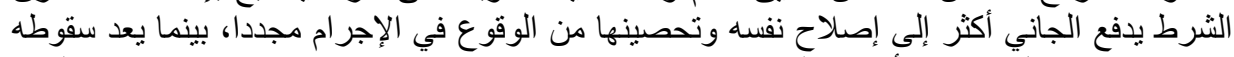

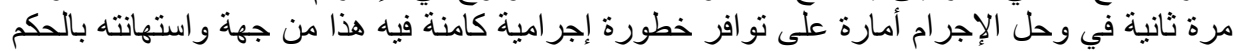

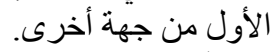

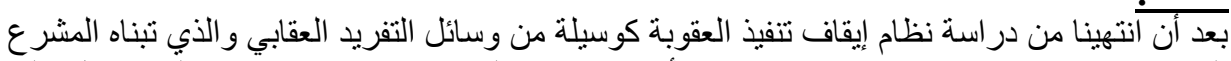

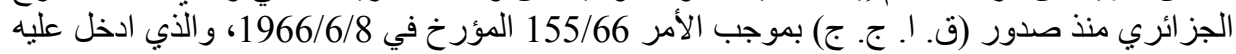

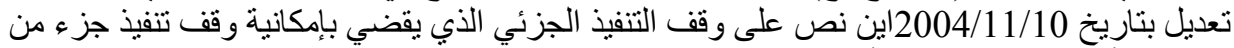
العقوبة الأصلية دون الجزء الأخر. و هو نظام يدخل في نطاق السلطة التقديرية للقاضي منى نو الفرت الثربة الثروط القانونية المتعلقة بالمجرم،

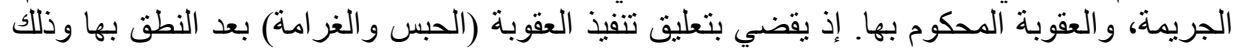

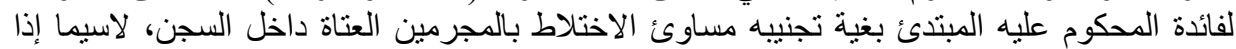

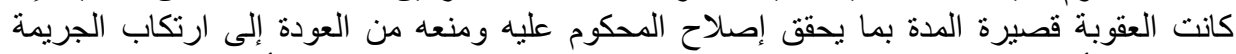

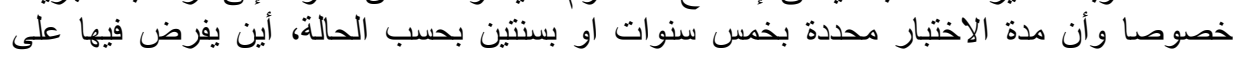

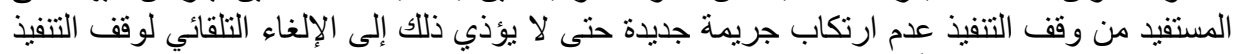

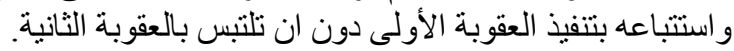

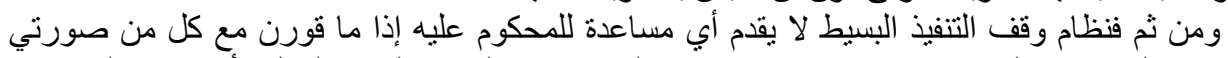

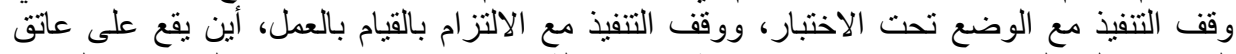

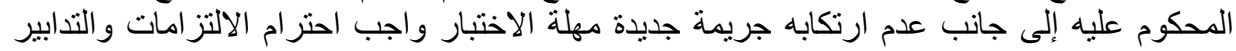

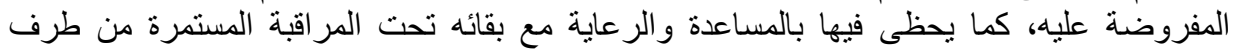
القضاء.

وبعد استعر اضنا الموجز للنظام القانوني لوقف التنفيذ يمكنتا عرض التوصيات ولنيات والاقتر احات التي تراءت

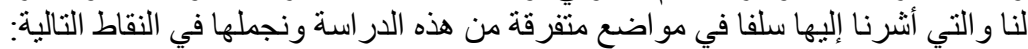

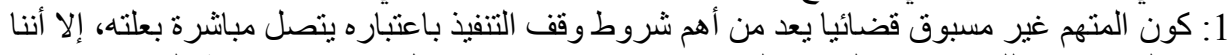

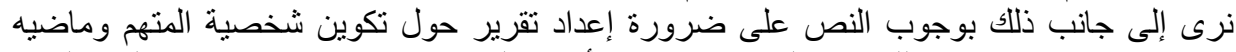
ودوافع إجرامه، بما يتيح للقاضي الجنائي الإحاطة أكثر بالمتهم ومعرفة مدى استحقي لثقاقه لهذا النظام وتحقيقه للردع الخاص. 2: التوسيع من مجال سلطة القاضي الجنائي في الحكم بإيقاف تنفيذ العقوبة ليشمل العقوبات التكميلية إلى ولى

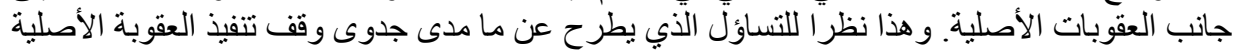

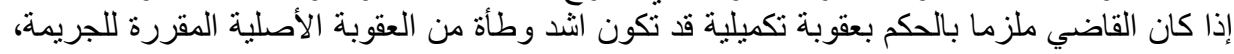

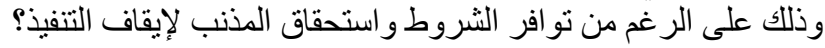

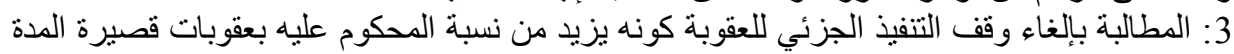

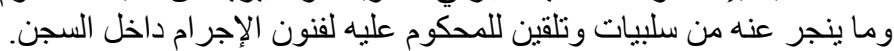

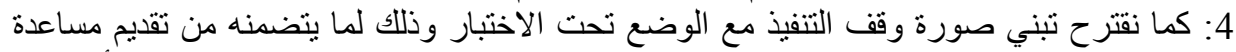

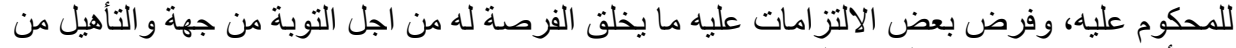
جهة أخرى مع بقائه تحت الرقابة القضائية.

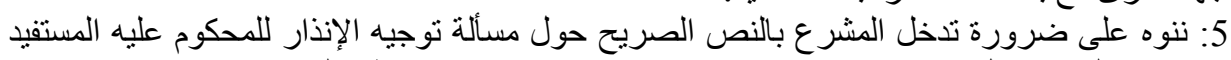

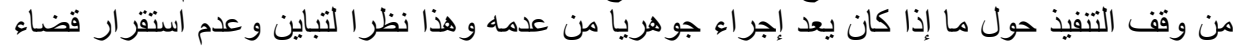


المحكمة العليا، مع تأكيدنا على عدم جعل هذا الإنذار قاعدة جوهرية يترتب على إغفالها البطلان وهذا

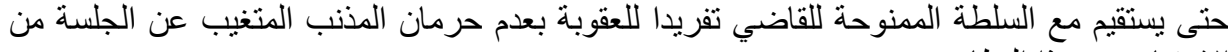

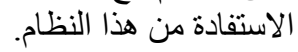

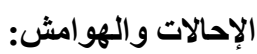

[1]. -مجحوده (احمد)، أزمة الوضوح في الإثم الجنائي في القانون الجزائري و القانون المقارن (الجزء

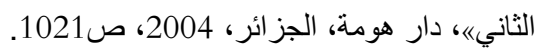

[2]. - نجيب حسني (محمود)، شرح قانون العقوبات القسم العام، الطبعة السادة، دار النهضة، القاهرة

1989، 1957، صناب حسن.

[3]. -Stefani (G) - Levasseur (G) - Bouloc (B), droit pénal général, Dalloz, 16 Édition.1997,N : 722,P 513.

[4]. -Larguier (J) , droit pénal général ,Dalloz,19 Édition,2003, p181.

[5]. - جروه (علي)، الموسوعة في الإجراءات الجز ائية، المجلد3 بعنوان في المحاكمة، 2006، ص681.

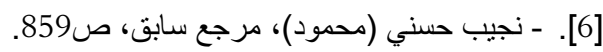

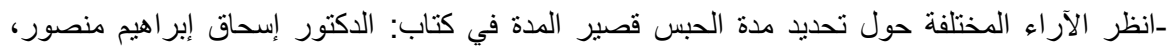

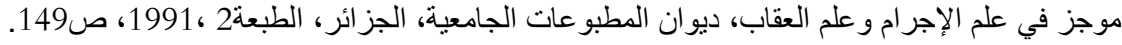

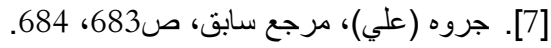

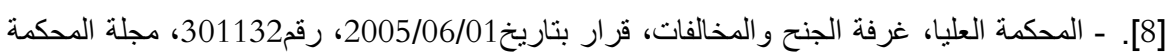

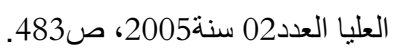

[9]. - انظر المادة 55من قانون العقوبات المصري رقم 2005/ 1937و المعدل بالقانون 2003/95.والتي

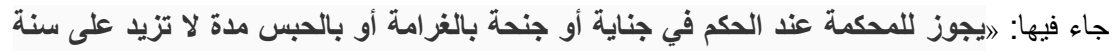

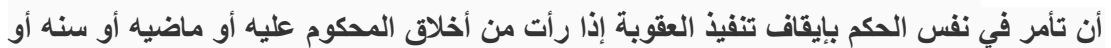

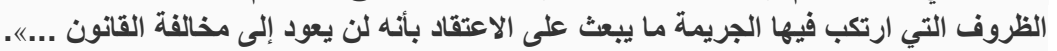

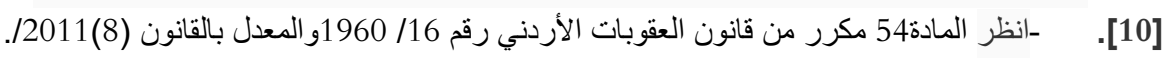

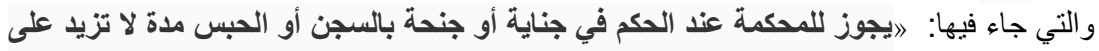

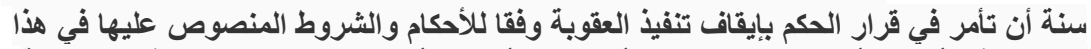

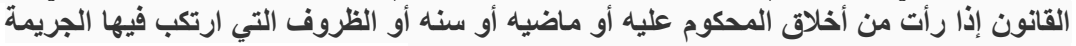

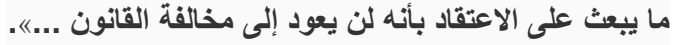

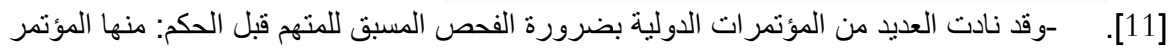

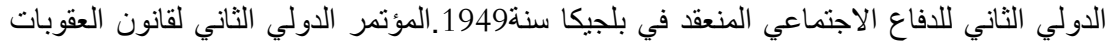

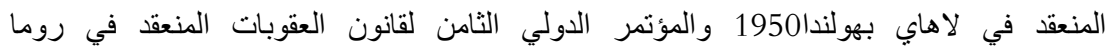

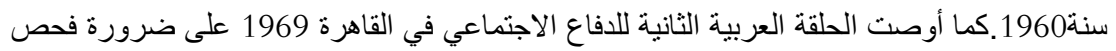

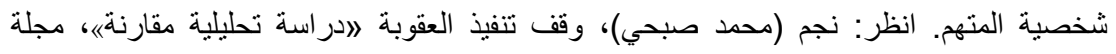

الحقوق تصدر عن كلية الحقوق بجامعة الكويت، العدد04، السنة172، جمادى الاولى1409 ديسمبر

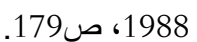

[12]. -Code Pénal Français .production de droit .Org .Édition 2015. 
Voir aussi : larguier (J), op .cit, p183،184 /add- Leroy (J), droit pénal général France, 2003, p426

[13]. Article 123/30 Code Pénal Français. Voir : Pradel (J), op .cit, p 656.

$$
\text { كذلك جروه (علي)، مرجع سابق، ص } 685 .
$$

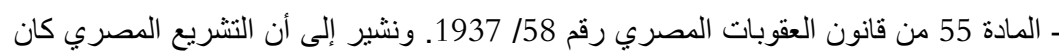

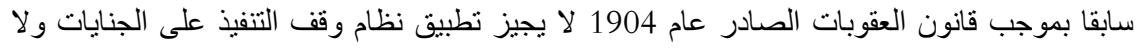

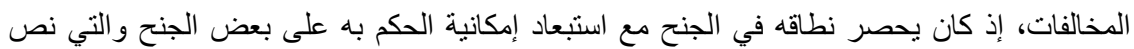

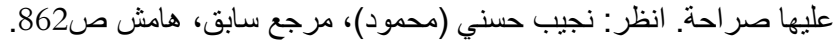

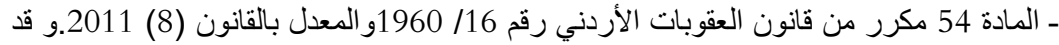

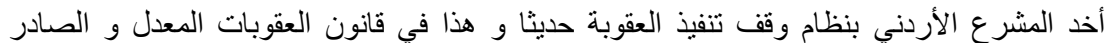

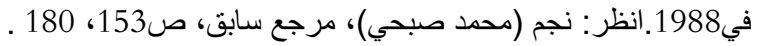

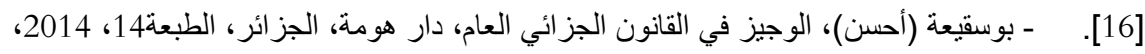
ص465.

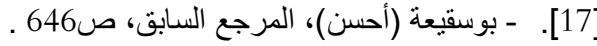

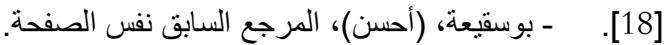

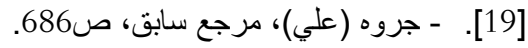

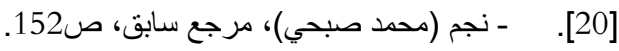

[21]. Béranger هو صاحب مشروع "قانون نظام وقف التنفيذ "إذ قدم اقتراحه هذا على مجلس

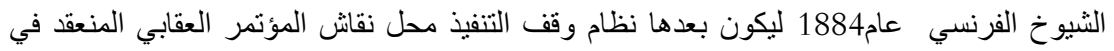

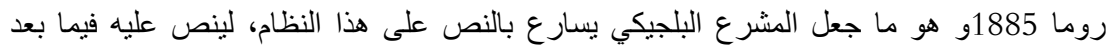

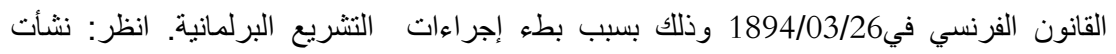

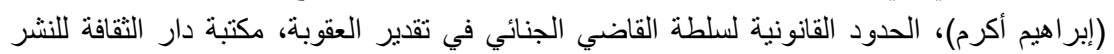

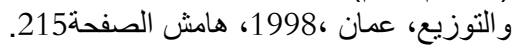

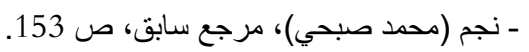

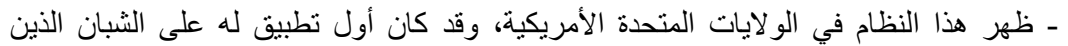

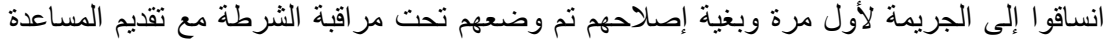

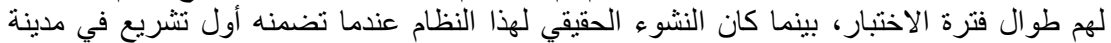

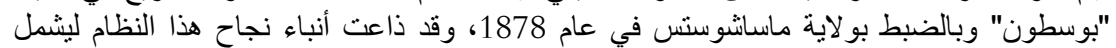

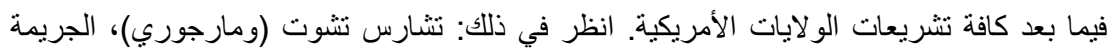

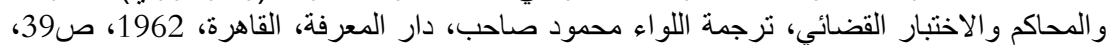

[24]. -Kolb (P) -leturmy (L), droit pénal général, gualino éditeur, paris, 2005, n423, p454.

[25]. -Leroy (J), op. cit. p428 . Add: Larguier (J), op .cit, p188 / kolb (P) -leturmy (L), op. Cit, n424, 425, p454.

[26]. -Larguier (J), op .cit, 189.

[27]. -Leroy (J), op .cit, p428 . 
[28]. - Larguier (J) ,op .cit, p191.

[29]. - -Larguier (J), op .cit, p192,193

[30]. -Kolb (P) - leturmy (L), op cit, N 430, p 458.

[31]. -kolb (P) - Leturmy (L), ibid.p 459

$$
\begin{aligned}
& \text { [32]. - جروه (علي)، مرجع سابق، ص690. } \\
& \text { [33]] - بوسقيعة (أحسن)، المرجع السابق، } 467 \text { ـ } 467 \text {. }
\end{aligned}
$$

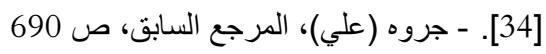

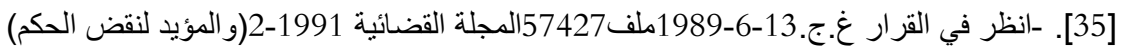

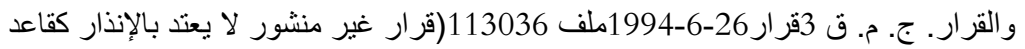

$$
\begin{aligned}
& \text { جوهرية ) بوسقيعة (أحسن)، ص ص } 469
\end{aligned}
$$

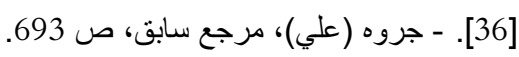

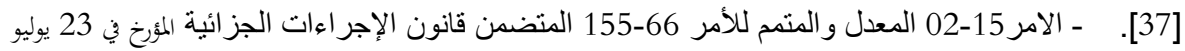

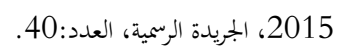

[38]. -Stefani (G) -Levasseur (G) -Bouloc (B), op. Cit, p 518.

$$
\begin{aligned}
& \text { [39]. - نجيب حسني (محمود)، مرجع سابق، ص } 871 \text { ـ } 871 .
\end{aligned}
$$

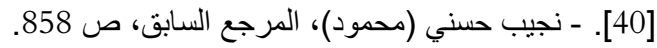

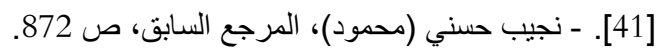

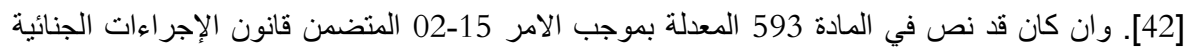

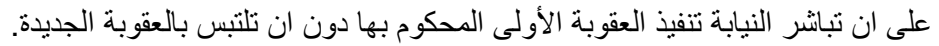

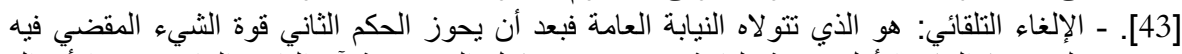

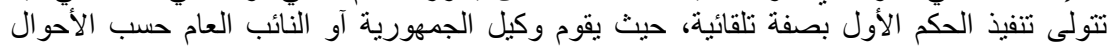

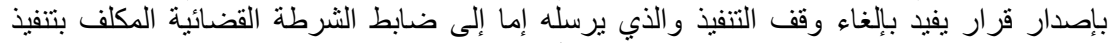

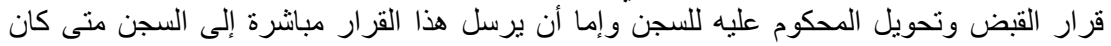

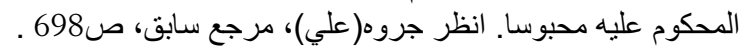

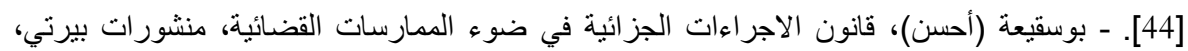

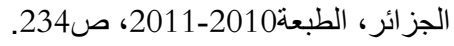

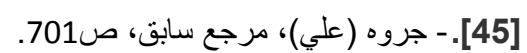

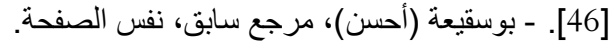

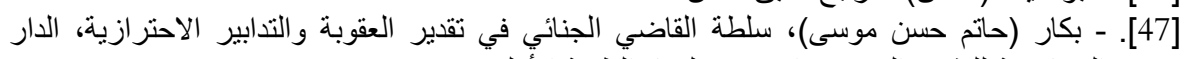

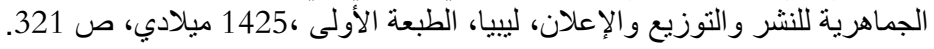

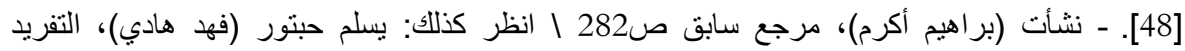

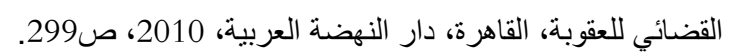

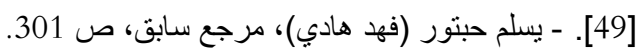

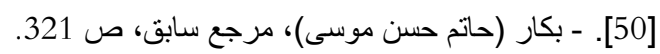

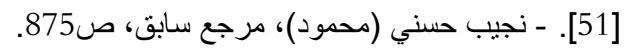

[52]. - -Larguier (j), Op .cit, p 186. 